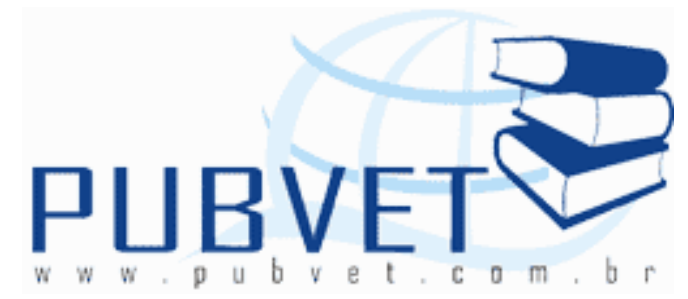

PUBVET, Publicações em Medicina Veterinária e Zootecnia.

\title{
Minerais e vitaminas para quelônios em cativeiro
}

Jamile da Costa Araújo ${ }^{1,4}$, Ewertton Souza Gadelha², Maria das Dores Correia Palha $^{3,4}$, Priscila Vieira e Rosa ${ }^{5}$

${ }^{1}$ Doutoranda do curso de Zootecnia da Universidade Federal de Lavras (UFLA). E-mail: jamilejca@yahoo.com.br

${ }^{2}$ Graduando do curso de Engenharia de Pesca da Universidade Federal Rural da Amazônia (UFRA)

${ }^{3}$ Professor (a) da Universidade Federal Rural da Amazônia (UFRA)

${ }^{4}$ Pesquisadora do Projeto Bio-Fauna - ISARH/UFRA

${ }^{5}$ Professora da Universidade Federal de Lavras (UFLA)

\section{Resumo}

Os animais necessitam de nutrientes para seu desenvolvimento, e os mesmos precisam estar em conformidade com a necessidade de cada organismo, portanto, quando o animal encontra-se em cativeiro deve-se oferecer uma dieta balanceada, para o alcance máximo do desempenho produtivo, da resistência imunológica ou da convalescença, no caso daqueles acometidos por doenças. Dentre os animais silvestres mantidos em cativeiro, encontram-se os quelônios, répteis com reconhecida finalidade zootécnica, cada vez mais valorizados na produção animal, pelo fato de sua carne e subprodutos serem apreciados para consumo humano. Entretanto, a nutrição ainda é um entrave na quelonicultura, demandando um alto custo. Portanto, objetiva-se nesta 
ARAÚJO, J.C. et al. Minerais e vitaminas para quelônios em cativeiro. PUBVET, Londrina, V. 7, N. 5, Ed. 228, Art. 1506, Março, 2013.

revisão reunir informações que auxiliem a fundamentar o fornecimento adequado de vitaminas e minerais para quelônios em cativeiro, sendo levado em consideração o grande número de espécies, fase de desenvolvimento e outros fatores. Visto que esses dois grupos de nutrientes são de extrema importância no organismo animal devido a carência afetar a homeostasia animal, tendo reflexos negativos na sua criação em cativeiro, e do excesso no meio ambiente, por conta da poluição ambiental. As fontes de suplementação também devem ser levadas em consideração, pois, podem entrar em associação com compostos orgânicos da ração formando quelatos e prejudicando a assimilação desses nutrientes pelo organismo. Além disso, cada fonte de suplementação possui qualidades químicas e nutritivas distintas. Porém, tal suplementação é uma alternativa para compensar a deficiência destes compostos nas rações fornecidas, as quais muitas vezes não são específicas para esses animais.

Palavras-chave: Animais silvestres, Nutrição, Quelonicultura.

\title{
Minerals and vitamins for chelonians in captivity
}

\begin{abstract}
Animals need nutrients to development, and they must comply with requirements of each organism, so that in ex situ condition should provide a balanced diet to possibility animals reach the maximum performance, that will also provide a more rapid recovery of disease and reduce agonistic behaviour and another stress. Among reptiles captive breeding, chelonians are one of the most common group in farming or ranching systems, with increasingly valued of its meat and by global products. However, nutrition still an obstacle in chelonian breeding systems, demanding a high cost. Therefore, this review aims to gather information that could help to support an adequate supply of vitamins and minerals for captive chelonians being taken into account the large number of species being farmed and other factors. Since these two groups of micronutrients are extremely important in the animal organism due to its
\end{abstract}


ARAÚJO, J.C. et al. Minerais e vitaminas para quelônios em cativeiro. PUBVET, Londrina, V. 7, N. 5, Ed. 228, Art. 1506, Março, 2013.

deficiency or excess affect the homeostasis animal, having a negative impact on their captive breeding, and excess in the environment, due to environmental pollution. We discuss data about sources of supplementation, since such nutrients can enter in association with organic compounds forming chelates diet and damaging the assimilation of nutrients by the body, and each source of supplementation have distinct nutrient and chemical qualities. However, such supplementation is an outlet for the deficiency of these compounds in the feed provided, which are often not specific to these animals.

Keywords: Wildlife, Nutrition, Turtle farming.

\section{INTRODUÇÃO}

A criação de animais silvestres com finalidade comercial é uma atividade ainda em desenvolvimento no Brasil. Mais que uma nova atividade comercial, promove a valorização dos recursos faunísticos nacionais e, ainda, representa uma fonte de proteína animal altamente adaptada às reais condições naturais do ambiente tropical sul-americano. Dentre estes animais encontram-se os quelônios amazônicos, com alto potencial para exploração zootécnica, particularmente por seu porte, sua alta prolificidade, rusticidade e pelo valor econômico de sua carne, produtos e subprodutos (Sá et al., 2004). Na Amazônia, a carne de quelônio é muito apreciada pelos nativos e também por turistas, que a consideram um alimento exótico. Por isso, restaurantes da região oferecem uma série de opções culinárias, onde o ingrediente principal é a carne destes répteis. Por sua ampla utilização, os quelônios foram alvo de crescente predação, com predominância de abastecimento do comércio ilegal, o que o levou a diminuição dos estoques naturais, devido a essa exploração desordenada.

Atualmente, no Brasil, a criação de quelônios para fins comerciais é normatizada pela Instrução Normativa no 169 de 20 de fevereiro de 2008 (Ibama, 2008), a fim de minimizar a comercialização ilegal e a exploração destes animais, estimulando a criação zootécnica de diversas espécies, com o objetivo de suprir a demanda do mercado. Porém, os dados sobre a nutrição 
ARAÚJO, J.C. et al. Minerais e vitaminas para quelônios em cativeiro. PUBVET, Londrina, V. 7, N. 5, Ed. 228, Art. 1506, Março, 2013.

desses animais ainda são limitados, considerando que se trata de um dos principais componentes dos custos de produção, e como um meio de otimizar a mesma e minimizar os custos, se faz de grande valia conhecer os níveis de exigência de vitaminas e minerais da espécie a ser cultivada e suas formas de suplementação. Principalmente, por conta das mudanças na exigência nutricional dos animais devido fatores como habitat (cativeiro ou vida livre), idade, estado reprodutivo, sexo, etc.

As vitaminas são essenciais para o bom funcionamento do metabolismo e, consequentemente, necessárias para saúde e manutenção das funções fisiológicas tais como, mantença, crescimento e reprodução (Bertechini, 2006). Já os minerais são nutrientes integrantes do corpo sob a forma sólida, através da rigidez do esqueleto e dentes, dos tecidos moles e músculos, como cofatores em diversos processos enzimáticos, entre outros, possuindo função reguladora orgânica (Franco, 1999). Não obstante, ressaltam-se que a deficiência e o excesso de vitaminas e minerais acarretam sérios problemas ósseos e metabólicos aos animais, sendo indispensáveis níveis corretos de suplementação desses nutrientes na dieta animal. Deste modo, em situação de desnutrição, o sistema imune é o primeiro a sofrer alterações, respondendo antes mesmo do sistema reprodutivo (Carciofi e Oliveira, 2007). Na tentativa de aumentar a disponibilidade para o animal, uma suplementação excessiva de minerais pode causar efeitos prejudiciais, acarretando na redução da ação metabólica de outros minerais, além de não contribuir para melhorar sua concentração no sangue e causar poluição ambiental (Kiefer, 2005). Visto que o desconhecimento dos níveis ideais de minerais e vitaminas faz com que as rações formuladas sejam abundantes nestes compostos, os quais muitas vezes não são utilizados pelos animais, sendo excretados, contaminando o meio ambiente, e gerando outro fator preocupante, o ambiental. Portanto, o objetivo desta revisão é reunir e analisar os dados sobre os níveis ideais de minerais e vitaminas e suas formas de suplementação em quelônios, levando em consideração os fatores limitantes, como o grande número de espécies, diferenças climáticas, entre outras. 
ARAÚJO, J.C. et al. Minerais e vitaminas para quelônios em cativeiro. PUBVET, Londrina, V. 7, N. 5, Ed. 228, Art. 1506, Março, 2013.

\section{Minerais}

\section{Cálcio e fósforo}

O cálcio ( $\mathrm{Ca}$ ) é o mineral mais abundante no esqueleto de animais, incluindo répteis, além de ser o principal mineral nas dietas destes organismos. Como maior constituinte mineral destes, representa entre $1 \%$ a $2 \%$ (Huang et al., 2003; Bertechini, 2006). Segundo Bertechini (2006), o Ca é essencial à formação óssea, para produção e qualidade da casca do ovo, além de participar da contração dos músculos esqueléticos e cardíacos. Este mineral torna-se o mineral mais abundante em quelônios por estar presente em grande quantidade em seu casco, o que aumenta a exigência dietética do mesmo quando comparados a outros animais. As principais fontes de origem animal são a farinha de carne e ossos, farinha de vísceras de aves, farinha de peixe, farinha de ossos calcinada e farinha de ostras. Dentre as fontes minerais estão o calcário, fosfato bicálcico, fosfato monocálcico e o fosfato monoamônio (Almeida, 2007). Já o fósforo é um macromineral que geralmente encontra-se, nas literaturas, correlacionado com o cálcio, pelo fato dos dois serem ativos na mineralização óssea. O fósforo também está presente na formação de ATP, sendo, portanto responsável pela geração de energia ao organismo, fundamental para a atividade de produção e reprodução animal, além de regular enzimas alostéricas (Bertechini, 2006).

$\mathrm{Na}$ nutrição de quelônios, segundo Huang et al. (2003), a farinha de peixe não deve ser utilizada como a principal fonte de cálcio para quelônios, pois contém baixos níveis deste mineral, não atendendo as suas necessidades. Em experimento com Pelodiscus sinensis (tartaruga-da-carapaça-molechinesa), os autores supracitados constataram que suplementando a dieta com carbonato de cálcio e fosfato de cálcio em níveis de $5,7 \%$ de Ca e $3 \%$ de $\mathrm{P}$, se obtêm um ótimo crescimento, concluindo que a maior suplementação de fósforo aumenta a deposição de cálcio nos órgãos e a cinza no corpo do animal. A relação de $\mathrm{Ca}: \mathrm{P}$ neste experimento correspondeu a 2,10 $\pm 0,02$. $\mathrm{Na}$ Tabela 1 encontram-se os valores de exigência e digestibilidade de fontes de suplementação de Ca e P, para quelônios, encontrados na literatura. 
ARAÚJO, J.C. et al. Minerais e vitaminas para quelônios em cativeiro. PUBVET, Londrina, V. 7, N. 5, Ed. 228, Art. 1506, Março, 2013.

Tabela 1. Valores de exigência vitamínico-mineral e digestibilidade em quelônios.

\begin{tabular}{|c|c|c|c|c|}
\hline Mineral & Suplemento(s) & Espécie & $\begin{array}{c}\text { Exigência/ } \\
\text { digestibilidade }\end{array}$ & Autores \\
\hline \multirow{3}{*}{ Cálcio } & $\begin{array}{c}\text { Fosfato de } \\
\text { cálcio/Carbonato } \\
\text { de cálcio }\end{array}$ & $\begin{array}{l}\text { Pelodiscus } \\
\text { sinensis }\end{array}$ & $5,7 \%$ & $\begin{array}{l}\text { Huang et al. } \\
\text { (2003) }\end{array}$ \\
\hline & $\begin{array}{c}\text { Lactato de } \\
\text { cálcio/Carbonato } \\
\text { de cálcio }\end{array}$ & $\begin{array}{c}\text { Geochelone } \\
\text { nigra }\end{array}$ & $\begin{array}{c}84 \% \\
\text { digestibilidade } \\
\text { média }\end{array}$ & $\begin{array}{l}\text { Liesegang et } \\
\text { al. (2001) }\end{array}$ \\
\hline & $\begin{array}{l}\text { Carbonato de } \\
\text { cálcio }\end{array}$ & $\begin{array}{l}\text { Testudo } \\
\text { hermanni }\end{array}$ & $\begin{array}{c}79 \pm 6 \% \\
\text { digestibilidade }\end{array}$ & $\begin{array}{l}\text { Liesegang et } \\
\text { al. (2007) }\end{array}$ \\
\hline \multirow{4}{*}{ Fósforo } & Fosfato de cálcio & $\begin{array}{l}\text { Pelodiscus } \\
\text { sinensis }\end{array}$ & $3 \%$ & $\begin{array}{l}\text { Huang et al. } \\
\quad(2003)\end{array}$ \\
\hline & $\begin{array}{c}\text { Fosfato de } \\
\text { cálcio/Carbonato } \\
\text { de cálcio }\end{array}$ & $\begin{array}{c}\text { Geochelone } \\
\text { nigra }\end{array}$ & $\begin{array}{c}91 \% \\
\text { digestibilidade }\end{array}$ & $\begin{array}{l}\text { Liesegang et } \\
\text { al. (2001) }\end{array}$ \\
\hline & $\begin{array}{c}\text { Fosfato de } \\
\text { cálcio/Carbonato }\end{array}$ & $\begin{array}{l}\text { Pelodiscus } \\
\text { sinensis }\end{array}$ & $2,10 \pm 0,02$ & $\begin{array}{l}\text { Huang et al. } \\
\text { (2003) }\end{array}$ \\
\hline & de cálcio & $\begin{array}{l}\text { Testudo } \\
\text { hermani }\end{array}$ & $\begin{array}{c}52 \pm 4 \% \text { de } \\
\text { digestibilidade }\end{array}$ & $\begin{array}{l}\text { Liesegang et } \\
\text { al. (2007) }\end{array}$ \\
\hline \multirow{3}{*}{ Ca:P } & $\begin{array}{c}\text { Lactato de } \\
\text { cálcio/Carbonato }\end{array}$ & $\begin{array}{l}\text { Geochelone } \\
\text { nigra }\end{array}$ & $6,1: 1$ & $\begin{array}{l}\text { Liesegang et } \\
\text { al. (2001) }\end{array}$ \\
\hline & de cálcio & $\begin{array}{l}\text { Quelônios } \\
\text { herbívoros } \\
\text { terrestres }\end{array}$ & $1,5-2: 16$ & $\begin{array}{c}\text { Massana e } \\
\text { Silvestre } \\
(2008)\end{array}$ \\
\hline & $\begin{array}{l}\text { Carbonato de } \\
\text { cálcio }\end{array}$ & $\begin{array}{l}\text { Testudo } \\
\text { hermani }\end{array}$ & $6: 1$ & $\begin{array}{l}\text { Liesegang et } \\
\text { al. (2007) }\end{array}$ \\
\hline Ferro & Citrato férrico & $\begin{array}{l}\text { Pelodiscus } \\
\text { sinensis }\end{array}$ & $\begin{array}{c}266 \text { e } 325 \\
\mathrm{mg} / \mathrm{kg}\end{array}$ & $\begin{array}{c}\text { Chu et al. } \\
(2007)\end{array}$ \\
\hline Magnésio & & $\begin{array}{l}\text { Testudo } \\
\text { hermani }\end{array}$ & $\begin{array}{c}52 \pm 2 \% \text { de } \\
\text { digestibilidade }\end{array}$ & $\begin{array}{l}\text { Liesegang et } \\
\text { al. (2007) }\end{array}$ \\
\hline Cobre & Sulfato de cobre & $\begin{array}{l}\text { Pelodiscus } \\
\text { sinensis }\end{array}$ & $4-5 \mathrm{mg} / \mathrm{kg}$ & $\begin{array}{l}\text { Wu et al. } \\
(2008)\end{array}$ \\
\hline Zinco & Sulfato de zinco & $\begin{array}{l}\text { Pelodiscus } \\
\text { sinensis }\end{array}$ & 35 a $46 \mathrm{mg} / \mathrm{kg}^{-1}$ & $\begin{array}{c}\text { Huang et al. } \\
\text { (2009) }\end{array}$ \\
\hline
\end{tabular}


ARAÚJO, J.C. et al. Minerais e vitaminas para quelônios em cativeiro. PUBVET, Londrina, V. 7, N. 5, Ed. 228, Art. 1506, Março, 2013.

As quantidades de Ca e $\mathrm{P}$ e também a relação dos mesmos na composição corpórea do animal é de grande valia no momento de se estabelecer as exigências. Por conta disso, dados de literatura estão apresentados na Tabela 2. Massana e Silvestre (2008) relatam que a relação Ca:P para quelônios herbívoros terrestres é de 1,5 - 2:16. Liesegang et al. (2001) constataram que tartarugas gigantes (Geochelone nigra) suplementadas com $7,33 \%$ de $\mathrm{Ca}$, numa relação $\mathrm{Ca}: \mathrm{P}$ de $6,1: 1$, alcançaram uma digestibilidade média de $84 \% \pm 3 \%$ para o Ca e de $91 \% \pm 2 \%$ para o $\mathrm{P}$.

\section{Zinco}

O zinco ( $\mathrm{Zn}$ ) está distribuído em todos os tecidos orgânicos, porém, as maiores concentrações deste elemento são encontradas no fígado, pele e pêlos (Bertechini, 2006). Este microelemento participa de vários sistemas enzimáticos, além de ser componente de muitas metaloenzimas, sendo essencial para o crescimento por estar envolvido em todo o processo de multiplicação celular (Bertechini, 2006). Para Carciofi e Oliveira (2007), a deficiência de zinco em animais silvestres resulta em extensivo dano aos linfócitos T, com atrofia do timo, alteração da síntese de linfócitos, resultando em marcada imunossupressão. Leva também a alterações epidérmicas associadas à maior penetração de agentes. Segundo Bertechini (2006), deficiências deste mineral ainda podem acarretar em problemas reprodutivos, pois o mesmo participa na formação e manutenção dos túbulos seminíferos, na espermatogênese e em todos os processos reprodutivos das fêmeas, além de atuar no encurtamento e engrossamento dos ossos longos, debilitando o animal e levando-o a morte. O descuido com os níveis apropriados de $\mathrm{Zn}$ afetará um dos principais focos da produção animal, representado pela atividade reprodutiva, causando impactos negativos, tornando a produção de quelônios uma atividade inviável. Para evitar tal risco é necessária uma atenção rigorosa aos níveis de exigência deste micromineral (Bertechini, 2006). 
ARAÚJO, J.C. et al. Minerais e vitaminas para quelônios em cativeiro. PUBVET, Londrina, V. 7, N. 5, Ed. 228, Art. 1506, Março, 2013.

Tabela 2. Concentração de Cálcio e Fósforo na composição corpórea de quelônios.

\begin{tabular}{|c|c|c|c|c|}
\hline Mineral & Espécie & Fonte/Substrato & Concentração & Autor(es) \\
\hline \multirow{16}{*}{$\mathrm{Ca}$} & \multirow{11}{*}{$\begin{array}{c}\text { Podocnemis } \\
\text { expansa }\end{array}$} & \multirow{2}{*}{ Casco } & $7843,33( \pm 51,32)$ & Scarlato e Gaspar \\
\hline & & & $\mathrm{mg} / 100 \mathrm{~g}$ & $(2007)$ \\
\hline & & \multirow{2}{*}{ Fígado } & $0,06( \pm 0,01)$ & \multirow{2}{*}{ Scarlato (2006) } \\
\hline & & & $\mathrm{mg} / 100 \mathrm{~g}$ & \\
\hline & & Sangue (Ca & $7,08 \pm 1,04 \mathrm{mg} / \mathrm{dL}$ & Santos et al. (2005) \\
\hline & & Sangue (cálcio & & \\
\hline & & ionizado) & $4,41 \pm 0,60 \mathrm{mg} / \mathrm{dL}$ & Santos et al. (2005) \\
\hline & & & & Gaspar e Silva \\
\hline & & Carne (macho) & $242 \mathrm{mg} / 100 \mathrm{~g}$ & (2009) \\
\hline & & Carne (fêmea) & $189 \mathrm{mg} / 100 \mathrm{~g}$ & Gaspar e Silva \\
\hline & & & & (2009) \\
\hline & & & & Kienzle et al. \\
\hline & & Casco (juvenis) & & (2006) \\
\hline & Rhinoclemmis & Casco (semi- & $\begin{array}{l}\angle 55 \pm \angle \angle 9 / K g \\
241+25 / 1 / 9\end{array}$ & Kienzle et al. \\
\hline & pulcherrima & adultos) & $\begin{array}{l}\angle 44 \pm \angle 5 \mathrm{~g} / \mathrm{kg} \\
244+21 \mathrm{~kg}\end{array}$ & (2006) \\
\hline & & Casco (adulto) & $\angle 44 \pm \angle 1 \mathrm{~g} / \mathrm{kg}$ & $\begin{array}{l}\text { Kienzle et al. } \\
\qquad(2006)\end{array}$ \\
\hline & & Casco & $\begin{array}{c}3000,0 \pm 55,22 \\
\mathrm{mg} / 100 \mathrm{~g}\end{array}$ & $\begin{array}{c}\text { Scarlato e Gaspar } \\
\text { (2007) }\end{array}$ \\
\hline & & Fígado & $\begin{array}{c}237,34 \pm 3,65 \\
\mathrm{mg} / 100 \mathrm{~g}\end{array}$ & Scarlato (2006) \\
\hline & Podocnemis & & & Santos et al. (2005) \\
\hline & expansa & Sangue & $5,21 \pm 1,22 \mathrm{mg} / \mathrm{dL}$ & Gaspar e Silva \\
\hline & & Carne (macho) & 536 mg/100g & (2009) \\
\hline Fósforo & & Carne (fêmea) & $524 \mathrm{mg} / 100 \mathrm{~g}$ & $\begin{array}{c}\text { Gaspar e Silva } \\
\text { (2009) }\end{array}$ \\
\hline
\end{tabular}

Kienzle et al.

(2006)

Kienzle et al.

(2006)

Kienzle et al.

(2006)

Ca:P Podocnemis expansa 
ARAÚJO, J.C. et al. Minerais e vitaminas para quelônios em cativeiro. PUBVET, Londrina, V. 7, N. 5, Ed. 228, Art. 1506, Março, 2013.

Além dos níveis de zinco na dieta, outro fator que merece atenção é a interação com outras substâncias, como algumas fontes proteicas que contêm ácido fítico as quais podem impedir o aproveitamento deste mineral, por formarem quelatos insolúveis. A presença de altos conteúdos de cálcio e fósforo no intestino delgado também interfere na absorção de zinco, formando compostos insolúveis, prejudicando o seu aproveitamento (Bertechini, 2006). Por conta disso, deve-se monitorar a quantidade de cálcio, ferro e a fonte proteica na ração animal.

Huang et al. (2009) em estudos com tartarugas-de-carapaça-molechinesa (Pelodiscus sinensis), durante dez semanas, concluíram que as exigências de zinco devem estar entre o intervalo de 35 a $46 \mathrm{mg} / \mathrm{kg}^{-1}$ para estes animais. Cousins e Hempe (1990), citados por Huang et al. (2009), relatam que no corpo do animal os níveis de Zn são relativamente constantes, na maioria dos tecidos moles, músculos, cérebro e coração. Entretanto no soro e nos ossos, são altamente influenciados pelo Zn na dieta, pois o Zn presente no soro é passivamente transportado para o corpo, para o funcionamento fisiológico normal, enquanto que o Zn em excesso é armazenado nos ossos (Tabela 3).

\section{Ferro}

O Ferro (Fe) está distribuído principalmente nos tecidos moles. A maior fração do ferro orgânico está na molécula de hemoglobina, representando de 60 a $70 \%$ do total presente no organismo. O restante está distribuído nos músculos (mioglobina), enzimas (citocromos e catalase), fígado (ferritina e hemociderina) baço, soro (transferrina), rins (transferrina), entre outras. Músculos, fígado e baço são órgãos estoques deste elemento. Este micromineral participa da molécula de hemoglobina e mioglobina que estão relacionadas ao transporte de $\mathrm{O}_{2}$ (respiração), de enzimas e coenzimas (citromo, peroxidação - cadeia respiratória), e de produtos (1 ovo $=1-1,5$ $\mathrm{mg}$ ). Por isso, é essencial para o crescimento dos animais, e sua deficiência pode causar anemia e diarréia (Bertechini, 2006; Chu et al., 2007). A forma 
ARAÚJO, J.C. et al. Minerais e vitaminas para quelônios em cativeiro. PUBVET, Londrina, V. 7, N. 5, Ed. 228, Art. 1506, Março, 2013.

mais indicada como suplemento alimentar é a forma ferrosa, por ser mais solúvel, sendo a sua disponibilidade diminuída com a presença de altas taxas de fosfato, fitatos e tanatos.

Tabela 3. Concentração de zinco na composição corpórea de quelônios.

\begin{tabular}{|c|c|c|c|c|}
\hline Mineral & Espécie & Fonte/Substrato & Concentração & Autor(es) \\
\hline \multirow[b]{5}{*}{ Zinco } & \multirow{3}{*}{$\begin{array}{c}\text { Podocnemis } \\
\text { expansa }\end{array}$} & Casco & $\begin{array}{c}5,66( \pm 0,21) \\
\mathrm{mg}\end{array}$ & $\begin{array}{c}\text { Scarlato e Gaspar } \\
(2007)\end{array}$ \\
\hline & & Fígado & $\begin{array}{c}2,60( \pm 0,22) \\
\mathrm{mg}\end{array}$ & Scarlato (2006) \\
\hline & & Carne & $5,6 \mathrm{mg} / 100 \mathrm{~g}$ & $\begin{array}{c}\text { Gaspar e Silva } \\
(2009)\end{array}$ \\
\hline & Chelonia mydas & Carne & $5,6 \mathrm{mg}$ & $\begin{array}{c}\text { Ruiter (1999) apud } \\
\text { Gaspar e Silva } \\
\text { (2009) }\end{array}$ \\
\hline & $\begin{array}{l}\text { Rhinoclemmis } \\
\text { pulcherrima }\end{array}$ & $\begin{array}{l}\text { Casco (juvenis) } \\
\text { Casco (semi- } \\
\text { adultos) } \\
\text { Casco (adulto) } \\
\text { Fígado (semi- } \\
\text { adultos) } \\
\text { Fígado (adulto) } \\
\text { Corpo (juvenis) } \\
\text { Corpo (semi- } \\
\text { adulto) } \\
\text { Corpo (adulto) }\end{array}$ & $\begin{array}{l}167 \pm 29 \mathrm{~g} / \mathrm{kg} \\
182 \pm 20 \mathrm{~g} / \mathrm{kg} \\
183 \pm 26 \mathrm{~g} / \mathrm{kg} \\
135 \pm 24 \mathrm{~g} / \mathrm{kg} \\
153 \pm 27 \mathrm{~g} / \mathrm{kg} \\
151 \pm 26 \mathrm{~g} / \mathrm{kg} \\
158 \pm 15 \mathrm{~g} / \mathrm{kg} \\
156 \pm 21 \mathrm{~g} / \mathrm{kg}\end{array}$ & $\begin{array}{l}\text { Kienzle et al. } \\
(2006) \\
\text { Kienzle et al. } \\
(2006) \\
\text { Kienzle et al. } \\
\text { (2006) } \\
\text { Kienzle et al. } \\
\text { (2006) } \\
\text { Kienzle et al. } \\
\text { (2006) } \\
\text { Kienzle et al. } \\
\text { (2006) } \\
\text { Kienzle et al. } \\
\text { (2006) } \\
\text { Kienzle et al. } \\
\text { (2006) }\end{array}$ \\
\hline
\end{tabular}

Este micromineral participa da molécula de hemoglobina e mioglobina que estão relacionadas ao transporte de $\mathrm{O}_{2}$ (respiração), de enzimas e coenzimas (citromo, peroxidação - cadeia respiratória), e de produtos (1 ovo = 1-1,5 mg). Por isso, é essencial para o crescimento dos animais, e sua deficiência pode causar anemia e diarréia (Bertechini, 2006; Chu et al., 2007). 
ARAÚJO, J.C. et al. Minerais e vitaminas para quelônios em cativeiro. PUBVET, Londrina, V. 7, N. 5, Ed. 228, Art. 1506, Março, 2013.

As exigências de ferro são maiores nas fases iniciais e de crescimento do animal, por ter uma maior demanda de síntese de mioglobina (Spinosa et al., 1996; Bertechini, 2006). Segundo Spinosa et al. (1996) a quantidade de ferro é controlada pela necessidade do organismo. Portanto, animais jovens por apresentarem um crescimento acelerado, requerem uma quantidade maior de ferro, quando comparados aos adultos.

Com base em análise de regressões derivadas a partir de parâmetros hematológicos e teores de ferro do tecido de tartarugas-de-carapaça-molechinesa, Chu et al. (2007) constataram que a exigência estimada foi de 266 e $325 \mathrm{mg} / \mathrm{kg}$, respectivamente, sendo usado como fonte de suplementação o citrato férrico. Já em pesquisa realizada com tartaruga-da-Amazônia (Podocnemis expansa), Santos et al. (2005) observaram média de 390,35 \pm $116,65 \mathrm{~g} / \mathrm{dL}$ de Fe no sangue. Esses animais foram alimentados com ração comercial (para peixes) possuindo $24 \%$ de proteína bruta e ocasionalmente recebiam frutas, verduras e legumes da estação, colhidos na própria fazenda (mandioca, cenoura, mamão, alface). Gaspar e Silva (2009), a partir da análise da carne de tartaruga-da-Amazônia, obtiveram um teor elevado de ferro, em média de $6 \mathrm{mg} / 100 \mathrm{~g}$ (Tabela 4). Esta Tabela demonstra, mais uma vez, a grande necessidade de estudos na área, além das grandes diferenças que podem ser encontradas entre as espécies de quelônios. 
ARAÚJO, J.C. et al. Minerais e vitaminas para quelônios em cativeiro. PUBVET, Londrina, V. 7, N. 5, Ed. 228, Art. 1506, Março, 2013.

Tabela 4. Concentração de ferro na composição corpórea de quelônios.

\begin{tabular}{|c|c|c|c|c|}
\hline Mineral & Espécie & Fonte/Substrato & Concentração & Autor(es) \\
\hline \multirow{3}{*}{ Ferro } & $\begin{array}{l}\text { Podocnemis } \\
\text { expansa }\end{array}$ & $\begin{array}{l}\text { Fígado } \\
\text { Sangue } \\
\text { Carne }\end{array}$ & $\begin{array}{c}32,76( \pm 0,92) \\
\mathrm{mg} \\
390,35 \pm 116,65 \\
\mathrm{~g} / \mathrm{dL} \\
6 \mathrm{mg} / 100 \mathrm{~g}\end{array}$ & $\begin{array}{l}\text { Scarlato (2006) } \\
\text { Santos et al. (2005) } \\
\text { Gaspar e Silva (2009) }\end{array}$ \\
\hline & $\begin{array}{c}\text { Rhinoclemmis } \\
\text { pulcherrima }\end{array}$ & $\begin{array}{l}\text { Casco (juvenis) } \\
\text { Casco (semi- } \\
\text { adultos) } \\
\text { Casco (adulto) } \\
\text { Fígado (semi- } \\
\text { adultos) } \\
\text { Fígado (adulto) } \\
\text { Corpo (juvenis) } \\
\text { Corpo (semi- } \\
\text { adulto) } \\
\text { Corpo (adulto) }\end{array}$ & $\begin{array}{c}287 \pm 143 \mathrm{~g} / \mathrm{kg} \\
404 \pm 224 \mathrm{~g} / \mathrm{kg} \\
785 \pm 512 \mathrm{~g} / \mathrm{kg} \\
8087 \pm 3856 \\
\mathrm{~g} / \mathrm{kg} \\
10712 \pm 3868 \\
\mathrm{~g} / \mathrm{kg} \\
311 \pm 104 \mathrm{~g} / \mathrm{kg} \\
473 \pm 125 \mathrm{~g} / \mathrm{kg} \\
746 \pm 327 \mathrm{~g} / \mathrm{kg}\end{array}$ & $\begin{array}{l}\text { Kienzle et al. (2006) } \\
\text { Kienzle et al. (2006) } \\
\text { Kienzle et al. (2006) } \\
\text { Kienzle et al. (2006) } \\
\text { Kienzle et al. (2006) } \\
\text { Kienzle et al. (2006) } \\
\text { Kienzle et al. (2006) } \\
\text { Kienzle et al. (2006) }\end{array}$ \\
\hline & $\begin{array}{l}\text { Pelodiscus } \\
\text { sinensis }\end{array}$ & $\begin{array}{l}\text { Sangue } \\
\text { Tecido }\end{array}$ & $\begin{array}{l}266 \mathrm{~km} / \mathrm{kg} \\
325 \mathrm{mg} / \mathrm{kg}\end{array}$ & $\begin{array}{l}\text { Chu et al. (2007) } \\
\text { Chu et al. (2007) }\end{array}$ \\
\hline
\end{tabular}

\section{Sódio e magnésio}

Sódio ( $\mathrm{Na}$ ) é um macromineral amplamente distribuído nos fluidos e tecidos moles. No organismo animal parte do sódio encontra-se no esqueleto em forma insolúvel, e a maior parte é encontrada nos fluidos extracelulares. Representa 93\% das bases do soro sanguíneo. Segundo Bertechini (2006), este mineral participa da estrutura do osso, e sua deficiência resulta em inapetência, redução da taxa de crescimento e apetite depravado.

O magnésio $(\mathrm{Mg})$ também é um macromineral intensamente associado ao cálcio e ao fósforo, pela sua distribuição e pelo seu metabolismo. De 50 a $70 \%$ de todo $\mathrm{Mg}$ é encontrado no esqueleto, o restante está amplamente 
ARAÚJO, J.C. et al. Minerais e vitaminas para quelônios em cativeiro. PUBVET, Londrina, V. 7, N. 5, Ed. 228, Art. 1506, Março, 2013.

distribuído nos tecidos moles exercendo funções vitais. Está envolvido em todas as reações de transferência de ligações ricas em energia (ATP-Mg, GTP$\mathrm{Mg}$, etc), ativa reações, e está estreitamente envolvido no metabolismo de carboidratos, gorduras, proteínas e ácidos nucléicos (Bertechini, 2006).

Gaspar e Silva (2009) a partir de análise da carne de tartaruga-daAmazônia, com 1,5 a $2 \mathrm{~kg}$ de peso vivo (PV), concluíram que os machos apresentavam um teor médio de $\mathrm{Mg}$ e de $\mathrm{Na}$ de 60,57 $\pm 2,66 \mathrm{mg} / 100 \mathrm{~g}$ e $351,00 \pm 7,69 \mathrm{mg} / 100 \mathrm{~g}$, e as fêmeas $65,86 \pm 5,08 \mathrm{mg} / 100 \mathrm{~g}$ e $369,71 \pm 4,35$ $\mathrm{mg} / 100 \mathrm{~g}$, respectivamente (Tabela 5). Estudo de digestibilidade com Testudo hermanni já foi efetuado e encontra-se na Tabela 1.

Tabela 5. Concentração de magnésio e sódio na composição corpórea de Podocnemis expansa.

\begin{tabular}{|c|c|c|c|c|}
\hline Mineral & Espécie & Fonte/Substrato & Concentração & Autores \\
\hline \multirow{5}{*}{ Magnésio } & \multirow{5}{*}{$\begin{array}{c}\text { Podocnemis } \\
\text { expansa }\end{array}$} & Sangue & $1,59 \pm 0,14 \mathrm{mg} / \mathrm{dL}$ & $\begin{array}{c}\text { Santos et al. } \\
(2005)\end{array}$ \\
\hline & & Fígado & $55,08( \pm 0,88)$ & $\begin{array}{c}\text { Scarlato e Gaspar } \\
\text { (2007) }\end{array}$ \\
\hline & & Carne & $60,57 \pm 2,66$ & Gaspar e Silva \\
\hline & & (macho) & mg/100g & (2009) \\
\hline & & Carne (fêmea) & $\begin{array}{c}65,86 \pm 5,08 \\
\mathrm{mg} / 100 \mathrm{~g}\end{array}$ & $\begin{array}{c}\text { Gaspar e Silva } \\
\text { (2009) }\end{array}$ \\
\hline Sódio & $\begin{array}{c}\text { Podocnemis } \\
\text { expansa }\end{array}$ & Fígado & $2,35( \pm 0,21)$ & $\begin{array}{c}\text { Scarlato e Gaspar } \\
\text { (2007) }\end{array}$ \\
\hline \multirow[b]{2}{*}{ Sódio } & \multirow{2}{*}{$\begin{array}{c}\text { Podocnemis } \\
\text { expansa }\end{array}$} & Carne (macho) & $\begin{array}{c}351,00 \pm 7,69 \\
\mathrm{mg} / 100 \mathrm{~g}\end{array}$ & $\begin{array}{c}\text { Gaspar e Silva } \\
\text { (2009) }\end{array}$ \\
\hline & & Carne (fêmea) & $\begin{array}{c}369,71 \pm 4,35 \\
\mathrm{mg} / 100 \mathrm{~g}\end{array}$ & $\begin{array}{c}\text { Gaspar e Silva } \\
\text { (2009) }\end{array}$ \\
\hline
\end{tabular}

\section{Outros minerais}

Além dos minerais citados, outros também são de relevante importância para os animais em questão, dentre eles podemos citar o cobre $(\mathrm{Cu})$, cobalto $(\mathrm{Co})$ e o manganês $(\mathrm{Mn})$. O cobre participa indiretamente da síntese de hemoglobina através da ativação da ferroxidase, além de ser 
ARAÚJO, J.C. et al. Minerais e vitaminas para quelônios em cativeiro. PUBVET, Londrina, V. 7, N. 5, Ed. 228, Art. 1506, Março, 2013.

essencial na formação óssea, e apresentar um papel fundamental na transferência de elétrons. Sua deficiência acarreta ao animal anemia e crescimento defeituoso dos ossos, o que não é muito comum, pois a maioria das fontes proteicas contém este mineral (Bertechini, 2006; Wu e Huang, 2008).

Scarlato e Gaspar (2007) obtiveram teores de cobre em casco da tartaruga-da-Amazônia de 0,22 $( \pm 0,02) \mathrm{mg} / 100 \mathrm{~g}$. E no fígado deste animal, foi encontrado um teor de 1,09 $( \pm 0,06) \mathrm{mg} / 100 \mathrm{~g}$ (Scarlato, 2006). Já Gaspar e Silva (2009), em estudo com a mesma espécie, constataram que na carne havia um teor de Cobre de 0,56 $\pm 0,14 \mathrm{mg} / 100 \mathrm{~g}$ em machos e 0,34 $\pm 0,13$ $\mathrm{mg} / 100 \mathrm{~g}$ em fêmeas. E com base em parâmetros hematológicos e de crescimento, Wu e Huang (2008) constataram que o nível de Cobre dietético recomendável para tartarugas-de-carapaça-mole-chinesa juvenis é de 4-5 $\mathrm{mg} / \mathrm{kg}$ (Tabela 6).

Quanto ao manganês, segundo Bertechini (2006), o baixo nível de Manganês no organismo animal provoca má formação óssea, além de ser essencial para o desenvolvimento da matriz orgânica óssea, a qual é composta largamente de mucopolissacarídeo, além de ser ativador de várias enzimas e essencial na reprodução e funcionamento normal do sistema nervoso central. Já a deficiência de potássio acarreta em baixo nível sanguíneo, ocasionando fraqueza muscular esquelética e dos músculos cardíacos e respiratórios, dentre suas várias funções no organismo, o potássio é exigido para atividades normais do coração, onde exerce efeitos opostos ao cálcio, reduzindo a contratilidade do músculo do coração (Bertechini, 2006). De acordo com Franco (1999), humanos e animais com deficiência de cobalto apresentam anemia perniciosa com perda de cobalto (vitamina B12), enquanto que superdoses experimentais em animais provocaram policitemia. Algumas pesquisas com manganês $(\mathrm{Mn})$, potássio $(\mathrm{K})$, e o cobalto (Co) já foram realizadas com quelônios, tais dados encontram-se na Tabela 7. 
ARAÚJO, J.C. et al. Minerais e vitaminas para quelônios em cativeiro. PUBVET, Londrina, V. 7, N. 5, Ed. 228, Art. 1506, Março, 2013.

Tabela 6. Concentração de cobre na composição corpórea de quelônios.

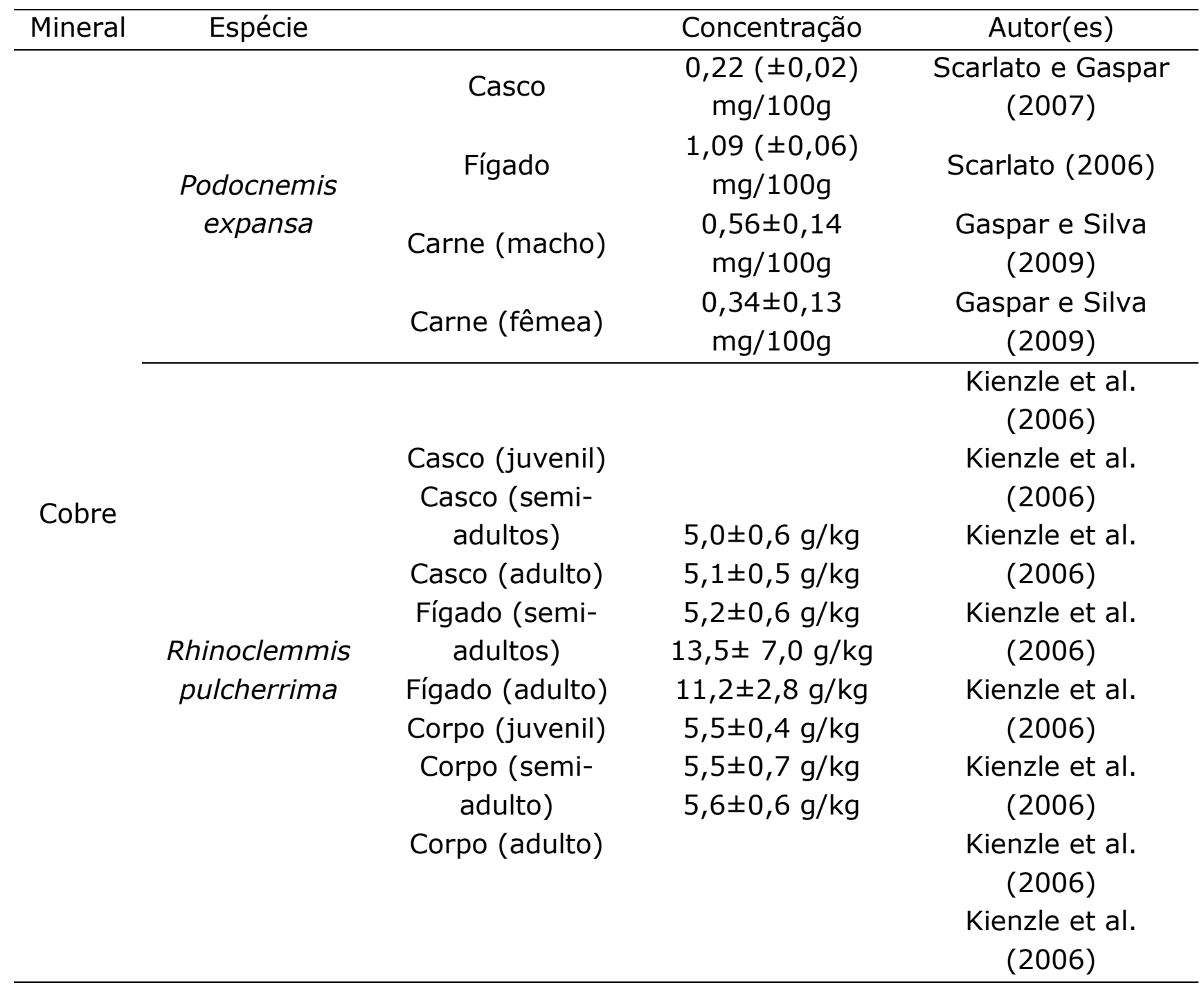


ARAÚJO, J.C. et al. Minerais e vitaminas para quelônios em cativeiro. PUBVET, Londrina, V. 7, N. 5, Ed. 228, Art. 1506, Março, 2013.

Tabela 7. Concentração de manganês, potássio e cobalto na composição corpórea de Podocnemis expansa.

\begin{tabular}{|c|c|c|c|c|}
\hline Mineral & Espécie & Fonte/Substrato & Concentração & Autor(es) \\
\hline \multirow{3}{*}{ Manganês } & \multirow{3}{*}{$\begin{array}{c}\text { Podocnemis } \\
\text { expansa }\end{array}$} & Casco & $1,02( \pm 0,21) \mathrm{mg}$ & $\begin{array}{l}\text { Scarlato e Gaspar } \\
\text { (2007) }\end{array}$ \\
\hline & & Carne (macho) & $\begin{array}{c}0,30 \pm 0,06 \\
\mathrm{mg} / 100 \mathrm{~g}\end{array}$ & $\begin{array}{c}\text { Gaspar e Silva } \\
\text { (2009) }\end{array}$ \\
\hline & & Carne (fêmea) & $\begin{array}{c}0,24 \pm 0,05 \\
\mathrm{mg} / 100 \mathrm{~g}\end{array}$ & $\begin{array}{c}\text { Gaspar e Silva } \\
\text { (2009) }\end{array}$ \\
\hline \multirow{3}{*}{ Potássio } & \multirow{3}{*}{$\begin{array}{l}\text { Podocnemis } \\
\text { expansa }\end{array}$} & Fígado & $4,72( \pm 0,27) \mathrm{mg}$ & Scarlato (2006) \\
\hline & & Carne (macho) & $\begin{array}{c}1190,28 \pm 7,94 \\
\mathrm{mg} / 100 \mathrm{~g}\end{array}$ & $\begin{array}{c}\text { Gaspar e Silva } \\
\text { (2009) }\end{array}$ \\
\hline & & Carne (fêmea) & $\begin{array}{c}1189,57 \pm 6,58 \\
\mathrm{mg} / 100 \mathrm{~g}\end{array}$ & $\begin{array}{c}\text { Gaspar e Silva } \\
(2009)\end{array}$ \\
\hline \multirow{3}{*}{ Cobalto } & \multirow{3}{*}{$\begin{array}{c}\text { Podocnemis } \\
\text { expansa }\end{array}$} & Casco & $0,79( \pm 0,06)$ & $\begin{array}{c}\text { Scarlato e Gaspar } \\
\text { (2007) }\end{array}$ \\
\hline & & Carne (macho) & $\begin{array}{c}0,23 \pm 0,05 \\
\mathrm{mg} / 100 \mathrm{~g}\end{array}$ & $\begin{array}{c}\text { Gaspar e Silva } \\
(2009)\end{array}$ \\
\hline & & Carne (fêmea) & $\begin{array}{c}0,23 \pm 0,05 \\
\mathrm{mg} / 100 \mathrm{~g}\end{array}$ & $\begin{array}{c}\text { Gaspar e Silva } \\
\quad(2009)\end{array}$ \\
\hline
\end{tabular}

\section{Vitaminas}

\section{Vitamina E}

A vitamina E é conhecida também como tocoferol. Segundo Bertechini (2006), a forma alfatocoferol é a mais importante nutricionalmente, e a absorção desta vitamina está relacionada com a digestão e absorção das gorduras, sendo facilitada pela bile e lipase pancreática. A vitamina E atua no metabolismo do carboidrato, na creatina, no metabolismo muscular, estimula a formação de anticorpos e antitóxicos no metabolismo celular. No geral, na deficiência de vitamina $E$ em peixes foi observada distrofia muscular, degeneração dos ácidos graxos no fígado, anemia e a redução da fertilidade (Harliog Lu e Barim, 2004).

Huang e Lin (2004) em estudos com tartaruga-de-carapaça-molechinesa constataram que um nível ótimo de vitamina $\mathrm{E}$ suplementado na dieta, 
ARAÚJO, J.C. et al. Minerais e vitaminas para quelônios em cativeiro. PUBVET, Londrina, V. 7, N. 5, Ed. 228, Art. 1506, Março, 2013.

de aproximadamente $88 \mathrm{IU} \mathrm{kg}^{-1}$, seria necessário para um bom crescimento deste quelônio. Zhou et al. (2004) testaram suplementações de vitamina E (0 , $50,250,500,1000$ e $5000 \mathrm{mg} / \mathrm{kg}$ ) na dieta por 4 semanas, com objetivo antiestressante em juvenis de tartaruga-de-carapaça-mole-chinesa. Os resultados mostraram que a fagocitose de células sanguíneas no grupo controle diminuiu significativamente após o estresse ácido, enquanto os outros cinco grupos não apresentaram alterações significativas quando comparadas antes do estresse. A atividade sérica bacteriolítica no grupo 0 (controle) e do grupo suplementado com $50 \mathrm{mg} / \mathrm{kg}$ de vitamina E diminuiu significativamente após o estresse ácido. Os outros quatro grupos não mostraram diferenças significativas comparadas àquelas antes do estresse. Resultados também mostraram que a fagocitose de células sanguíneas e atividade bactericida do soro foram significativamente melhoradas nos animais que ingeriram dietas com 250 e $500 \mathrm{mg} / \mathrm{kg}$ de suplementação de vitamina E (Tabela 8). Apesar de níveis de suplementação de 250 e $500 \mathrm{mg} / \mathrm{kg}$ serem bem satisfatórios, deve-se levar em consideração que o estudo foi efetuado com animais juvenis, portanto tal suplementação pode não ser adequada para outras fases do animal.

Tabela 8. Valores de exigência de vitaminas para quelônios.

\begin{tabular}{|c|c|c|c|}
\hline Vitamina & Espécie & Exigência & Autores \\
\hline & $\begin{array}{l}\text { Pelodiscus } \\
\text { sinensis }\end{array}$ & $88 \mathrm{IU} / \mathrm{kg}$ & $\begin{array}{l}\text { Huang e Lin } \\
\qquad(2004)\end{array}$ \\
\hline Vitamina $\mathrm{E}$ & $\begin{array}{c}\text { Pelodiscus } \\
\text { sinensis }\end{array}$ & $250-500 \mathrm{mg} / \mathrm{kg}$ & $\begin{array}{l}\text { Zhou et al. } \\
\text { (2004) }\end{array}$ \\
\hline Vitamina C & $\begin{array}{l}\text { Pelodiscus } \\
\text { sinensis } \\
\text { Pelodiscus } \\
\text { sinensis }\end{array}$ & $\begin{array}{c}500-10.000 \\
\mathrm{mg} / \mathrm{kg} \\
500 \mathrm{mg} / \mathrm{kg}\end{array}$ & $\begin{array}{c}\text { Zhou et al. } \\
\text { (2005) } \\
\text { Zhou et al. } \\
(2003)\end{array}$ \\
\hline
\end{tabular}

\section{Vitamina C}

O ácido ascórbico, também conhecido como vitamina $C$ é necessário para a formação dos corticóides, e, consequentemente, está envolvido na 
ARAÚJO, J.C. et al. Minerais e vitaminas para quelônios em cativeiro. PUBVET, Londrina, V. 7, N. 5, Ed. 228, Art. 1506, Março, 2013.

resposta imune dos animais. É participante no metabolismo dos aminoácidos aromáticos, transporte de elétrons, agente redutor da enzima Fe-alfacetoglutarato hidrolase, assim como é responsável pela deposição da fibrina, colágeno e polissacarídeos dentro dos vacúolos que são formados para isolar o microrganismo patogênico invasor pelos lisossomos. Logo, deficiências desta vitamina podem inibir o processo de vacuolização (Wedemeyer, 1997; Bertechini, 2006). Porém, durante os períodos de estresse, crescimento e reprodução os animais necessitam de uma maior concentração desse nutriente, o que pôde ser observado mesmo para as espécies que sintetizam essa vitamina. Se essa necessidade superar a capacidade do organismo sintetizar a vitamina $C$, quedas na concentração sérica de ascorbato podem ocorrer. Dessa forma é indicado o oferecimento desse nutriente para animais que estejam sofrendo algum tipo de estresse ou injúria, ou em períodos de reprodução (Carciofi e Oliveira, 2007). Zhou et al. (2005) afirmam que o estresse ácido diminui a atividade bacteriolítica, contudo quando adicionado a ração um teor de $500-10.000 \mathrm{mg} \mathrm{kg}^{-1}$ de vitamina C, a diminuição da atividade bacteriolítica abrandou (Tabela 8). Este pode ser o resultado da capacidade antioxidante da vitamina $\mathrm{C}$, de prevenção da superoxidação das células produtoras de lisozima e, assim, manutenção da estrutura da membrana celular e função celular. Os autores também concluíram que a suplementação desta vitamina com os teores previamente citados, foi capaz de amenizar a queda da taxa de fagocitose proveniente do estresse.

Zhou et al. (2005) em experimentos com tartarugas-de-carapaçamole-chinesa, concluíram que a suplementação de vitamina $\mathrm{C}$ em quantidades maiores que $250 \mathrm{mg} \mathrm{kg}^{-1}$ é necessária para reduzir os efeitos adversos do estresse ácido. Zhou et al. (2003) suplementaram na ração de tartaruga-decarapaça-mole-chinesa juvenis doses de $0 ; 250 ; 500 ; 2500 ; 5000$; e 10000 $\mathrm{mg} / \mathrm{kg}^{-1}$ de vitamina $C$ por quatro semanas. A suplementação de vitamina $C$ teve efeitos significativos sobre a taxa de crescimento específico e no fígado. $\mathrm{A}$ taxa específica de crescimento atingiu o pico no grupo alimentado com dieta de $500 \mathrm{mg} / \mathrm{kg}^{-1}$ (Tabela 8). 
ARAÚJO, J.C. et al. Minerais e vitaminas para quelônios em cativeiro. PUBVET, Londrina, V. 7, N. 5, Ed. 228, Art. 1506, Março, 2013.

\section{Vitamina D}

A vitamina D é essencial para a manutenção da homeostase do cálcio e, portanto, extremamente importante para o desenvolvimento, crescimento e manutenção de um esqueleto saudável nos vertebrados. $O$ tempo normalmente gasto exposto à luz solar direta varia substancialmente entre as famílias, gêneros e espécies de tartarugas e cágados. Isto implica em grandes diferenças na sensibilidade da pele para a síntese de vitamina D3 e/ou diferenças na dependência da exposição de alimentos versus a luz solar para satisfazer as necessidades de vitamina D. Chelydrideos e Kinosternideos parecem ser capazes de obter vitamina $D$ suficiente a partir de seu alimento, pois em grande parte são carnívoros (Purgley et al., 2009). Purgley et al. (2009) observaram que os níveis de vitamina D3 plasmática em Chelonia mydas em confinamento, começaram a declinar a partir do $4^{\circ}$ ao $5^{\circ}$ mês e continuaram a diminuir até os 8 anos. O que demonstra a deficiência dessa vitamina em condições de cativeiro e indica a necessidade de suplementação.

Licht (1994) comprovou que a proteína carreadora de tiroxina (TBP) e a proteína carreadora de D3 (DBP), presentes em mamíferos, são a mesma em Trachemys scripta. O fato destas proteínas carreadoras transportarem D3 e T4 deve ser levado em consideração, principalmente porque uma alta suplementação de D3 irá influenciar no transporte de T4, alterando assim a taxa de crescimento do animal. Portanto, tal suplementação deve ser cautelosa e monitorada durante longos períodos.

\section{CONSIDERAÇÕES FINAIS}

Em face ao exposto, pode-se considerar que vitaminas e minerais são essenciais para 0 bom desenvolvimento de quelônios. E que o desconhecimento dessas exigências acaba comprometendo o crescimento, a engorda e a reprodução desses animais quando criados em cativeiro. Estudos na área de nutrição de quelônios ainda são escassos e concentram-se em algumas espécies, especialmente em condições in situ, havendo lacunas que devem merecer esforços de pesquisa. Dentre elas, estudos sobre as espécies 
ARAÚJO, J.C. et al. Minerais e vitaminas para quelônios em cativeiro. PUBVET, Londrina, V. 7, N. 5, Ed. 228, Art. 1506, Março, 2013.

amazônicas e sobre as exigências de animais em cativeiro, podem contribuir para subsidiar programas de conservação ex situ ou in situ. Podendo ainda o melhor conhecimento dessas exigências alimentares quanto aos minerais e vitaminas, subsidiar indicadores ecológicos e clínicos para o monitoramento de populações em vida livre, inclusive quanto a segurança alimentar em habitats naturais. Por outro lado, podem servir de base para a formulação de protocolos para a suplementação vitamínica e mineral em dietas de quelônios, como alternativas para corrigir deficiências destes compostos nas rações fornecidas em cativeiro, considerando que muitas vezes não são específicas, sendo comum o uso de ração para peixes, entre outras. Entretanto, deve-se ter cautela para evitar excessos no fornecimento desses nutrientes, uma vez que podem acarretar problemas tanto no organismo animal como no ambiente.

\section{REFERÊNCIAS BIBLIOGRÁFICAS}

Almeida, C.G. Fontes e Disponibilidade de Cálcio e Fósforo Para a Tartaruga-da-Amazônia Podocnemis expansa Criada em Cativeiro. Dissertação (Mestrado). Universidade Estadual Paulista, Centro de Aquicultura. 2007; pp. 89.

Bertechini, A.G. Nutrição de monogástricos. Lavras: Ufla. 2006; pp. 301.

Brasil, Instituto Brasileiro de meio ambiente e dos Recursos Naturais Renováveis. Instrução Normativa no 169, de 20 jan. 2008, que institui e normatiza as categorias de uso e manejo da fauna silvestre em cativeiro em território brasileiro. Brasília: Ministério do Meio Ambiente, 2008. Disponível em: <http://www.ibama.gov.br/sisbio/legislacao.php?id_arq=39>. (29-052011).

Carciofi, A.C.; Oliveira, L.D. Doenças nutricionais. In: Cubas, Z.S.; Silva, J.C.R; Catão- Dias, J.L. Tratado de animais silvestres. ${ }^{\circ}$ edição. São Paulo: Editora Roca, 2007; pp. 847-851.

Chu, J.-H.; Chen, S.-M.; Huang, C.-H. Effect of dietary iron concentrations on growth, hematological parameters, and lipid peroxidation of soft-shelled turtles, Pelodiscus sinensis. Aquaculture, 2007; 7: 532-537.

Franco, G. Tabela de composição química dos alimentos, 9 ed. São Paulo: Atheneu, 1999. $307 p$.

Gaspar, A.; Silva, T.J.P. Composição nutricional da carne da tartaruga-da-Amazônia (Podocnemis expansa) criada em cativeiro e em idade de abate. Revista do Instituto Adolfo Lutz, São Paulo, 2009; 68: 419-425.

Harliog Lu, M.M.; Barim, O. The effect of dietary vitamin E on the pleopodal egg and stage-1 juvenile numbers of freshwater crayfish Astacus leptodactylus (Eschscholtz, 1823). Aquaculture, 2004; pp. 267-276.

Huang, C.-H.; Lin, W.-Y. Effects of dietary vitamin E level on growth and tissue lipid peroxidation of soft-shelled turtle, Pelodiscus sinensis (Wiegmann). Aquaculture Research, 35: 948-954. 
Huang, C.-H.; Lin, W.-Y.; Wu, S.-M. Effect of dietary calcium and phosphorus supplementation in fish meal-based diets on the growth of soft-shelled turtle Pelodiscus sinensis (Wiegmann). Aquaculture Research, 2003; 34: 843-848.

Huang, S -C.; Chen, S.-M.; Huang, C.-H. Effects of dietary zinc levels on growth, serum zinc, hematological parameters and tissue trace elements of soft-shelled turtles, Pelodiscus sinensis. Aquaculture Nutrition, 2009; pp. 1-6.

Kienzle, E.; Kopsch, G.; Koelle, P.; Clauss, M. Chemical Composition of Turtles and Tortoises. The J. Nutr., 2006; 136:2053S-2054S.

Kiefer, C. Minerais quelatados na nutrição de aves e suínos. Revista Eletrônica Nutritime, 2005; 2:206-220. Disponível em: <http://nutritime.com.br/arquivos_internos/artigos/023v2n3p206_220_mai2005_.pdf>. Acessado em 29-05-2011.

Licht, P. Thyroxine-binding protein represents the major vitamin D-binding protein In: The plasma of the turtle, Trachemys scripta. Gen. Comp. Endocrinol, 1994; pp: 82-92.

Liesegang, A.; Hatt, J.-M.; Nijboer, J.; Forrer, R. Wanner, M.; Isenbügel, E. Influence of different dietary calcium levels on the digestibility of $\mathrm{Ca}, \mathrm{Mg}$, and $\mathrm{P}$ In: Captive-born juvenile galapagos giant tortoises (Geochelone Nigra). Zoo. Biology, 2001; pp. 367-374.

Liesegang, A.; Hatt, J.-M.; Wanner, M. Influence of different dietary calcium levels on the digestibility of $\mathrm{Ca}, \mathrm{Mg}$ and $\mathrm{P}$ in Hermann's tortoises (Testudo hermanni). Journal of Animal Physiology and Animal Nutrition, 2007; 91:459-464.

Massana, J.S.; Silvestre, A.M. Manejo y alimentación de tortugas y galápagos en cautividad. Consulta de Difusión Veterinaria, 2008; 16:33-42.

Purgley, H.; Jewll, J.; Deacon, J.E.; Winokur, R.M.; Tripoli; V.M. Vitamin D3 in captive green sea turtles (Chelonia mydas). Chelonian Conservation and Biology, 2009; 8:161-167.

Sá, V.A.; Quintanilha, L.C.; Freneau, G.E.; Luz, V.L.F.; Borja, A.L.R.; Silva, P.C. Crescimento ponderal de filhotes de tartaruga gigante da Amazônia (Podocnemis expansa) submetidos a tratamento com rações isocalóricas contendo diferentes níveis de proteína bruta. Revista Brasileira de Zootecnia, 2004; 33:2351-2358.

Santos, A.L.Q.; Malta, T.S.; Mundim, A.V.; Alves Júnior, J.R.F.; Carvalho, S.F.M. Variação dos constituintes bioquímicos sanguíneos de tartarugas-da-Amazônia (Podocnemis expansa, Schweigger - 1812) (Testudinata) mantidas em criatório comercial. Archives of Veterinary Science, 2005; 10: 1-8.

Scarlato, R.C. Composição centesimal do casco e fígado da tartaruga-da-Amazônia (Podocnemis expansa) criada em cativeiro em idade de abate. Dissertação (Mestrado). Universidade Federal Rural do Rio de Janeiro, Instituto de Tecnologia, 2006: pp. 80.

Scarlato, R.C.; Gaspar, A. Composição nutricional do casco da tartaruga-da-Amazônia (Podocnemis expansa) criada em cativeiro e em idade de abate. Revista Brasileira de Ciência e Tecnologia de Alimentos, Campinas, 2007; 27:41-44.

Spinosa, H.S.; Górniak, S.L.; Bernardi, M.M. Farmacologia aplicada à medicina veterinária. Rio de janeiro: Guanabara Koogan, 1996; pp. 545.

Wedemeyer, G.A. Effects of rearing conditions on the health and physiological quality of fish in intensive culture. In: Iwama, G.K.; Pickering, A.D.; Sumpter, J.P.; Schreck, C.B. Fish stress and health in aquaculture. Cambridge: Cambridge University Press. 1997; pp. 35-72.

Wu, G.-S.; Huang, C.-H. Estimation of dietary copper requirement of juvenile soft-shelled turtles, Pelodiscus sinensis. Aquaculture, 2008; 280:206-210. 
Zhou, X.; Xie, M.; Niu, C.; Sun, R. The effects of dietary vitamin C on growth, liver vitamin C and serum cortisol in stressed and unstressed juvenile soft-shelled turtles (Pelodiscus sinensis). Comparative Biochemistry and Physiology, 2003; pp: 263-270.

Zhou, X.-Q.; Niu, C. -J.; Sun, R.-Y. The effects of vitamin E on antiacid stress ability in juvenile soft-shelled turtles (Pelodiscus sinensis). Comparative Biochemistry and Physiology, 2004; pp:299-305.

Zhou, X. -Q.; Niu, C.-J.; Sun, R.-Y. The effect of vitamin C on stress withstanding capability in the juvenile soft-shelled turtle (Pelodiscus sinensis). Aquaculture Nutrition, 2005; pp:169174. 